\title{
In memoriam: John Ross, Jr
}

\author{
Gianluigi Condorelli ${ }^{1} \cdot$ Gerd Heusch ${ }^{2}$
}

Published online: 1 July 2019

(c) The Author(s) 2019

\section{Sit tibi terra levis}

On 11 April, 2019 , John Ross Jr, a legendary figure in cardiovascular medicine who influenced generations of cardiovascular researchers and cardiologists over the last six decades, passed away at his home in La Jolla, California. He left this world shortly after the disappearance of his beloved companion, Dr. Lola Romanucci-Ross, a prominent cultural anthropologist and colleague at the University of California San Diego (UCSD). They had been married since 1972 (Fig. 1).

Describing Dr. Ross's contributions to modern cardiovascular medicine in a few words is of the utmost difficulty, as his interests spanned many areas of myocardial disease, allowing him to make many landmark observations (Circ Res 110, 2012, 1166-1168).

Dr. Ross was a man of action with extraordinary intellectual abilities but with a quiet demeanour and a witty sense of humour. Of Scottish ancestry, Dr. Ross was born in New York City to Dr. John Ross $\mathrm{Sr}$ - an otorhinolaryngologist, from whom he inherited a passion for surgery and a sense of equality in treating patients-and Ms. Janet Moulderfrom whom he inherited a passion for art and music [5]. After receiving his MD from Cornell University, he started

This article has been co-published with permission in the European Heart Journal, Cardiovascular Research, and Basic Research in Cardiology. All rights reserved. (C) The Authors(s). These articles are identical except for minor stylistic and spelling differences in keeping with each journal's style. Either citation can be used when citing this article.

Gianluigi Condorelli

gianluigi.condorelli@hunimed.eu

$\triangle$ Gerd Heusch

Gerd.Heusch@uk-essen.de

1 Humanitas Research Hospital, Humanitas University, Rozzano, 20089 Milan, Italy

2 Institute for Pathophysiology, West German Heart and Vascular Center, University of Essen Medical School, 45122 Essen, Germany post-graduate training in surgery at Johns Hopkins University Hospital in 1956. There, Dr. Ross made the first critical encounter of his career: Dr. Alfred Blalock, who at that time was experimenting with his landmark procedure, the Blalock-Taussig shunt, which turned "blue babies" back to pink. Struck by Dr. Ross's capabilities, Dr. Helen Taussig offered him a research position in surgery at the National Heart Institute (NHI) of the National Institutes of Health (NIH), Bethesda, Maryland. There, Ross made his first seminal contribution: experiments on dogs combined with his typical keen clinical observations led him to devise a long needle with a curved tip to measure pressure in the left atrium and ventricle (LV) and to perform left heart angiography $[4,5]$. The procedure, called retrograde catheterization of the LV-which also allowed the measurement of pressure gradients and mitral and aortic valve orifice areas-was performed with success on humans in 1958, and rapidly substituted for the transseptal left heart catheterization (TSLHC) method.

In 1960, Dr. Ross returned to New York to finish his clinical training. Then, in 1962, Dr. Eugene Braunwaldappointed head of the new cardiology branch at NHI/NIHappointed him section head of the cardiac catheterization laboratories as well as an experimental laboratory. Fate had it that Dr. Edmund Sonnenblick was also a member of the group at the NHI at that time, studying the mechanics of isolated cardiac muscle. Dr. Ross started applying some of Dr. Sonnenblick's concepts on preload, afterload and inotropic state to isolated muscle, in the context of human disease, using the TSLHC technique. Through studies on humans in which LV end-diastolic pressure, stroke work index, LV end-systolic pressure and stroke volume index were measured, Dr. Ross was the first to demonstrate that the failing human LV has an enhanced sensitivity to increased afterload [4]. Experiments performed with Dr. James Covell aimed at evaluating cardiac performance after modification of preload and afterload (in particular, afterload modified during a single diastolic interval while leaving other hemodynamic variables unchanged) led Dr. Ross to develop the concept of "afterload mismatch with limited preload 


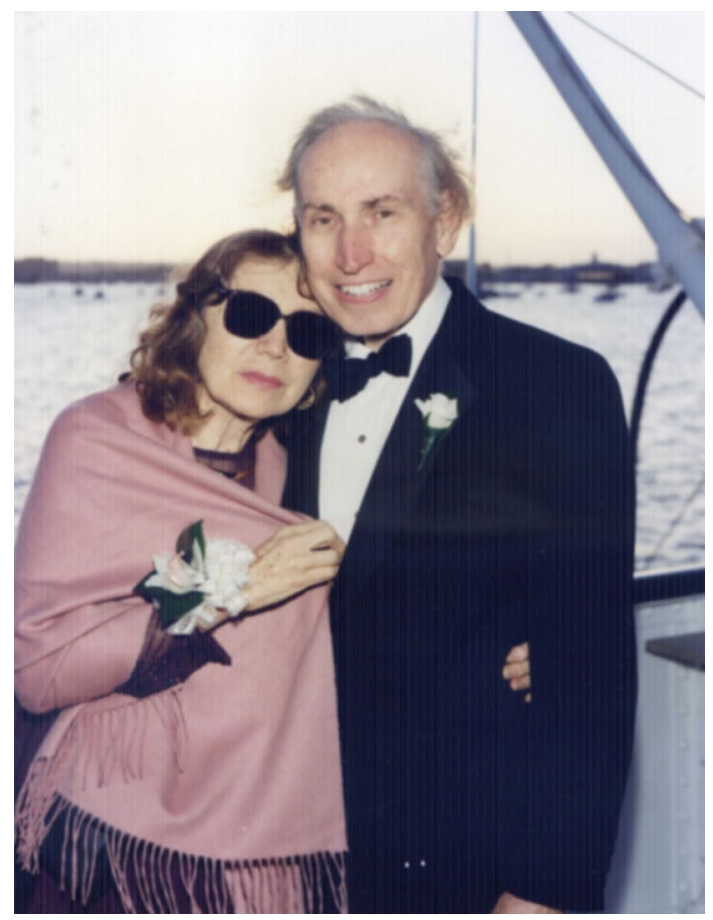

Fig. 1 Lola Romanucci-Ross and John Ross Jr (Courtesy of Deborah Nightingale)

reserve", a principle fundamental for understanding heart failure pathophysiology, that had profound therapeutic consequences [4]. That "golden age" at NHI was summarized in a historic book-which we jealously keep in our personal libraries-entitled "Mechanisms of Contraction of the Normal and Failing Heart" [1].

In 1968, Dr. Ross was invited by Dr. Braunwald-who had become the founding chair of the Department of Medicine at the newly established University of California San Diego (USCD) - to join the faculty as Chief of the Division of Cardiology, a position he kept until 1991. He would stay at UCSD until his retirement. There, Dr. Ross started a new line of investigation on the pathophysiology of myocardial ischemia. The NHI launched a new initiative on acute myocardial infarction, and Dr. Ross was awarded a large grant on the topic, which he held for decades. At the Seaweed Canyon Laboratory - his experimental cardiology facility near the cliffs facing the Pacific Ocean-Dr. Ross first demonstrated that coronary reperfusion after prolonged coronary occlusion was beneficial as it could decrease infarct size (Peter Libby, then a medical student, was a co-author) [4]. Those experiments laid the basis for subsequent studies on humans. As Dr. Ross wrote many times, the landmark GISSI clinical trials-conducted in Italy 14 years after his studies-demonstrated the clinical value of his experimental findings, determining that coronary reperfusion after thrombolysis with streptokinase significantly reduces mortality [4,
5]. In Seaweed Canyon Laboratory, Dr. Ross recruited an Artus-like assembly of most talented researchers, including physiologists from the US (Kim Gallagher, Brian Guth) and physicians from Europe (Bertrand Crozatier, Otto Hess, Gerd Heusch, Ciro Indolfi, Rainer Schulz, Eric Thaulow and others) and Asia (Shigetake Sasayama, Masunori Matsuzaki, Shunichi Miyazaki, Byung-Hee Oh and others) and made further seminal contributions to the understanding of myocardial ischemia - the persistence of recruitable coronary dilator reserve in ischemic myocardium, perfusion-contraction matching as the underlying mechanism of myocardial hibernation, and the pivotal role of tachycardia and alpha-adrenergic coronary vasoconstriction in exerciseinduced myocardial ischemia [2]. Aware of the revolutionary importance of molecular biology and following the Advisory Council of the NHLBI-NIH, he initiated a program at UCSD on the molecular basis of cardiac diseases. In collaboration with Dr. Ken Chien, he had the vision and was instrumental in directing Dr. Howard Rockman to develop a miniaturized technique for the hemodynamic assessment in mice, paving the way for cardiac phenotyping of genetically modified animals. Dr. Ross conducted the first studies using viral vectors for transferring genes to the myocardium of murine models of cardiac diseases [3].

Throughout his career, Dr. Ross received many prizes in recognition of his outstanding achievements. Among other duties, he was President of the American College of Cardiology and editor at Circulation. Together with Professors Dirk Brutsaert and Shigetake Sasayama, he created a network of scientists working on cardiac function and biology, establishing the La Jolla-Kyoto-Antwerp Conferences, which rotates through the three continents. Most importantly, he left an indelible legacy by mentoring an immense number of investigators, many of whom have become professors and chairs of departments in the USA, Japan and Europe. The field he ploughed for half of a century is still fertile, at UCSD and elsewhere throughout the world.

Acknowledgements We are indebted to Drs. Ju Chen, Robert S. Ross, and Howard A. Rockman for critical reading and to Dr. Deborah Nightingale for the photo.

\section{References}

1. Braunwald E, Ross J Jr, Sonnenblick EH (1968) Mechanisms of contraction of the normal and failing heart, 1st edn. Little, Brown and Company, Boston

2. Ross J Jr (1991) Myocardial perfusion-contraction matching. Circulation 83:1076-1083

3. Ross J Jr (2003) From pump to molecules. Circ Res 92:480-481

4. Ross J Jr (2009) A 50-year research journey. From laboratory to clinic. Circ J 73:3-12

5. Ross J Jr (2014) Odyssey of a physician-scientist. Create space independent publishing platform 